\title{
Ecological and health risk assessment of heavy metals in soil and Chinese herbal medicines
}

\author{
Chunyan Meng $(\mathbb{D} \cdot$ Peng Wang $\cdot$ Zhuolu Hao $\cdot$ Zhenjie Gao $\cdot$ Qiang Li $\cdot$ \\ Hongxia Gao $\cdot$ Yingli Liu $\cdot$ Qingzhao Li $\cdot$ Qian Wang $\cdot$ Fumin Feng
}

Received: 18 December 2020/ Accepted: 15 May 2021/Published online: 1 June 2021

(C) The Author(s), under exclusive licence to Springer Nature B.V. 2021

\begin{abstract}
As medicinal plants can accumulate harmful metals from the native soil, people's consumption of these materials may cause the human body to accumulate toxic metal elements. This has given rise to people's concerns about the quality and safety of Chinese medicinal materials. This research aims to determine the levels of $\mathrm{Cr}, \mathrm{Ni}, \mathrm{Cu}, \mathrm{Zn}, \mathrm{As}, \mathrm{Cd}, \mathrm{Hg}$ and $\mathrm{Pb}$ in four medicinal plant species (Aster tataricus L.f., Salvia miltiorrhiza Bge, Radix Aucklandiae, Scutellaria baicalensis Georgi) and their native soil. All samples were collected from Qian'an city, beside Yanshan Mountain Range in Tangshan city, east Hebei Province, north China. The contents of heavy metals we detected in the soil conformed to the current
\end{abstract}

Supplementary Information The online version contains supplementary material available at https://doi.org/10.1007/ s10653-021-00978-z.

C. Meng $\cdot$ P. Wang $\cdot$ Z. Hao $\cdot$ Q. Li .

H. Gao · Y. Liu - Q. Li · Q. Wang

School of Public Health, North China University of

Science and Technology, Tangshan, Hebei 063210,

People's Republic of China

Z. Gao

Qian'an Hospital of Traditional Chinese Medicine,

Tangshan, Hebei 064400, People's Republic of China

F. Feng $(\bowtie)$

College of Life Sciences, North China University of

Science and Technology, Tangshan, Hebei 063210,

People's Republic of China

e-mail: fm_feng@sina.com limits. However, the $\mathrm{Cd}$ and $\mathrm{Hg}$ in the soil had a very high potential ecological risk because of their contents higher than the base level of local soil. The contents of $\mathrm{Cu}, \mathrm{Cd}, \mathrm{Hg}$ and $\mathrm{Pb}$ in some medicinal herbs exceeded the standards. The content of $\mathrm{Cu}$ in Radix Aucklandiae exceeded the standard by 3 times, and others exceeded the standard by less than one time. The comprehensive health risk assessment of heavy metals with chronic non-carcinogenic effects for human body showed that none of the four medicinal herbs can create a health risk. Thus, there is no strong positive correlation between heavy metal pollution in medicinal herbs and that in the native soil. Further research should be investigated to the connection between the heavy metal levels in the soil and plants, and the comprehensive effects of soil, air and irrigation water on heavy metal pollution of Chinese herbal medicines. We also recommend that Chinese herbal medicines should be cultivated and gathered only from controlled or uncontaminated areas.

Keywords Chinese herbal medicine $\cdot$ Soil $\cdot$ Heavy metals - Ecological risk assessment $\cdot$ Health risk assessment

\section{Introduction}

Chinese herbal medicine is a valuable resource of traditional medicine in China. It has been used for 
thousands of years and has been widely spread to countries all over the world (Cheng, 2000). Meanwhile, it is also playing a vital role in the treatment of COVID-19 (Y. Li et al. 2020; Liu et al. 2020). Although Chinese herbal medicine is commonly perceived as natural and harmless remedy, it has potential safety hazard, such as excessive of heavy metals and toxicity (Zeiner \& Juranović Cindrić, 2017). With the popularization of Chinese medicinal materials, people have paid more attention to the health and safety of Chinese medicinal materials. Excessive accumulation of pollutants, particularly heavy metal pollution, in the soil of crops or herbal medicine has been in the limelight due to its bioamplification function and durability ( $\mathrm{Hu}$ et al. 2014; Jiang et al. 2018).

Some heavy metals are essential to the organism, such as $\mathrm{Cu}, \mathrm{Mn}$ and $\mathrm{Zn}$, which serve as part of proteins and enzymes in human body with the function of enhancing interaction and deactivating enzyme activity; however, they may also cause chronic poisoning after accumulation in some organs of the human body (Ur Rehman et al., 2018). Therefore, it is harmful for human body to ingest too much essential heavy metals. Meanwhile, other heavy metals are unnecessary and toxic to the organism. Herbal medicines may contain high amounts of harmful metals for hardly biodegradable, such as $\mathrm{As}, \mathrm{Cd}$ or $\mathrm{Pb}$, which could be absorbed from soil via roots, from air via wet or dry deposition or after being contaminated during processing (Adeyolanu et al., 2016; Zeiner \& Juranović Cindrić, 2017). Thus, they are enriched in human body by food chain for thousand folds, which is equal to biological amplification (C. Liu, Qin, et al., 2018; Liu, Wang, et al., 2018; Nagajyoti et al. 2010). The World Health Organization (WHO) has established maximum concentration limits for harmful elements in order to ensure the safe use of herbs (1996). China, as well as the rest of the world, has also posed strict limits on the contents of heavy metals in soil (AEPA, 1995; Environment, 2018) and in medicines (MFTEC, 2005) (Commission, 2020) with the purpose of ensuring human health. However, this will not fully guarantee all Chinese herbal medicines conformance.

The contents of heavy metals in herbal medicines often exceed safety limits especially if they have been cultivated or collected in contaminated areas (Barthwal et al., 2008; Glavač et al., 2017). As a matter of fact, the quality of herbs is decisively influenced by the environment (soil, nutrients, pollution, etc.) where they have been grown (Bonari et al., 2018; Zeiner \& Juranović Cindrić, 2017). Therefore, many reports focused on the health risk assessment of heavy metals in Chinese herbal medicine (Nan et al., 2020; Wang et al., 2019; Zuo et al., 2020a; Zuo et al., 2020b), as well as environmental and health risk assessment in soils (Z. Li et al., 2014; Yang et al., 2018). However, a few researches discussed comprehensively both on the herbals and its native soil (Glavač et al., 2017; Jalali \& Karimi Mojahed, 2020). Soil is not only the growing environment but also one of the main sources of heavy metal pollution of herbal medicines (Glavač et al., 2017). Therefore, it is vital to detect the metal levels and assess hazard in herbs and their native soil, so as to ensure the quality and safety of herbs and to determine any potential contamination.

The herbs studied in this paper named Aster tataricus L.f.(short for AL), Salvia miltiorrhiza Bge(short for SB), Radix Aucklandiae (short for RA) and Scutellaria baicalensis Georgi (short for SG), respectively, which are commonly used in China. The main purpose of this paper was to determine the heavy metal pollution status of these four Chinese herbal medicines and their native soils and to assess the ecological and health risk for them. We have tested 8 harmful elements, including $\mathrm{Cr}, \mathrm{Ni}, \mathrm{Cu}, \mathrm{Zn}, \mathrm{As}, \mathrm{Cd}$, $\mathrm{Hg}$ and $\mathrm{Pb}$, to conduct their risk assessment.

\section{Materials and methods}

Study area and sample collection

Qian'an City $\quad\left(\mathrm{N} \quad 39^{\circ} 51^{\prime} \sim 40^{\circ} 15^{\prime}, \quad \mathrm{E}\right.$ $118^{\circ} 26^{\prime} \sim 118^{\circ} 55^{\prime}$ ), nestling at the southern foot of the Yanshan Mountains and along the bank of the Luanhe River, is located in the northeast of Hebei Province, China. It has a typical semi-humid monsoon climate. The experimental samples were collected from medicinal planting area in Qian'an City, in the fall of 2014 and 2015. The sampled area was shown in Supplementary Fig. 1. According to the principle of grid method, 10 sampling areas were selected in the medicinal planting area, and samples were collected from 7 sample points. In each sampling site, one herb sample and one native soil sample were collected and brought back to the laboratory for drying. The specific sample information is shown in Supplementary Table 1. 
Analysis of the heavy metal in the samples

The powdered samples of both the soil and herbals (0.2 g each) were sieved through a 100-mesh screen, digested with $\mathrm{HNO}_{3}$ (Premium pure, Sigma, USA) using a microwave digestion system (MARS $\mathrm{X}$ System, CEM Corporation, USA). The digestion programs used are shown in Supplementary Table 2. After digestion, the residual acid was driven at $150{ }^{\circ} \mathrm{C}$ until the digestion solution volumes were reduced to about $1 \mathrm{~mL}$ and transferred to a $50-\mathrm{mL}$ volumetric flask which was treated by pre-soak acid to remove heavy metals, then washed and diluted with $1 \% \mathrm{HNO}_{3}$ to $50 \mathrm{~mL}$. The digestion solution was filtrated $(0.45 \mu \mathrm{m}$, PES filter, China). Then analysis of the total contents of heavy metals $(\mathrm{Cr}, \mathrm{Ni}, \mathrm{Cu}, \mathrm{Zn}, \mathrm{As}, \mathrm{Cd}$, $\mathrm{Hg}$ and $\mathrm{Pb}$ ) in herbs and soils was carried out by Inductively Coupled Plasma Mass Spectrometry (ICPMS) (Agilent 7500a, Agilent Technologies, USA) based on the following method (shown in Supplementary Table 3).

The standard fluid information used in ICP-MS was as follows: standard solution of $\mathrm{Cr}, \mathrm{Ni}, \mathrm{Cu}, \mathrm{Zn}, \mathrm{As}, \mathrm{Cd}$, $\mathrm{Hg}, \mathrm{Pb}$ (National Research Center for Reference Materials, China); internal standard solution of Sc, Ge, Y, Tb, In, Bi (Agilent Technologies, USA); mass spectrometric tuning solution of $\mathrm{Li}, \mathrm{Ce}, \mathrm{Y}, \mathrm{Tl}, \mathrm{Co}$ (Technologies, USA).

For analytical quality control, blank and duplicate samples were used during the process. To compensate for the signal drift and matrix effects, an internal standard was added to the blanks, calibration standard and samples. The relative standard deviation (RSD) of the 8 elements was between $1.2 \%$ and $3.8 \%$, and the recovery rate was from $86.3 \%$ to $107.2 \%$.

Evaluation model of heavy metal pollution in soil

Hakanson's evaluation model was applied in the present paper to evaluate the pollution level of the soil at the medicinal planting area (Hakanson, 1980). There are various models to evaluate the ecological risk of heavy metals in soils, such as Nemerow's Pollution Index (NPI), Geoaccumulation Index (Igeo), Pollution Load Index (PLI) (Mohammadi et al., 2020; Tang et al., 2019). Well Hakanson's ecological hazard index method is a widely recognized quantitative ecological risk assessment index, taking into account not only the concentration but also the toxicity of heavy metals
(Hakanson, 1980). Although first put forward in 1980, the index is still in use today (Long et al., 2021; Mohammadi et al., 2020). The formulas are as follows:

$C_{\mathrm{f}}^{\mathrm{i}}=\frac{C^{\mathrm{i}}}{C_{\mathrm{n}}^{\mathrm{i}}}$

$E_{\mathrm{r}}^{\mathrm{i}}=T_{\mathrm{r}}^{\mathrm{i}} \times C_{\mathrm{f}}^{\mathrm{i}}$

$\mathrm{RI}=\sum_{\mathrm{i}}^{\mathrm{m}} E_{\mathrm{r}}^{\mathrm{i}}=\sum_{\mathrm{i}}^{\mathrm{m}} T_{\mathrm{r}}^{\mathrm{i}} \times C_{\mathrm{f}}^{\mathrm{i}}=\sum_{\mathrm{i}}^{\mathrm{m}} T_{\mathrm{r}}^{\mathrm{i}} \times \frac{C^{\mathrm{i}}}{C_{\mathrm{n}}^{\mathrm{i}}}$

In Eq. (1): $C_{\mathrm{f}}^{\mathrm{i}}$ is the pollution coefficient of heavy metal $i$ in the soil; $\mathrm{C}^{\mathrm{i}}$ is the measured concentration of heavy metal $i\left(\mathrm{mg} \mathrm{kg}^{-1}\right) ; \mathrm{C}_{\mathrm{n}}^{\mathrm{i}}$ is the soil background value of heavy metal $i\left(\mathrm{mg} \mathrm{kg}^{-1}\right)$;

In Eq. (2): $E_{r}^{i}$ is the potential ecology of heavy metal $i$; $\mathrm{T}_{\mathrm{r}}^{\mathrm{i}}$ is the hazard index which represents the toxicity coefficient of heavy metal $i$;

The biotoxicity coefficient of nine heavy metals is defined by the potential ecological hazard index method as (Y. Liu, Qin, et al., 2018; Liu, Wang, et al., 2018): $\mathrm{Hg}=40>\mathrm{Cd}=30>\mathrm{As}=10>$ $\mathrm{Cu}=\mathrm{Ni}=\mathrm{Pb}=5>\mathrm{Cr}=2>\mathrm{Mn}=\mathrm{Zn}=1$;

In Eq. (3): $R I$ is the aggregate potential ecological hazard index of every determined heavy metal in the soil. The evaluation criteria are shown in Table 1.

Non-carcinogenic health risk assessment of heavy metals in Chinese herbal medicines

The potential non-carcinogenic risk assessment adopts the target hazard quotient method (THQ) to evaluate the health risks for long-term use of heavy metal elements. The THQ method, proposed by the US Environmental Protection Agency (USEPA), can provide information about the potential hazards of heavy metals to the human body and has been applied to risk assessment of heavy metals in many studies (Yang et al., 2018; Li et al., 2014; Zhou et al., 2018). The formula is as follows:

Table 1 Standards of potential ecological risk index (Hakanson, 1980)

\begin{tabular}{llll}
\hline$E_{r}^{i}$ & $\begin{array}{l}\text { Ecological risk } \\
\text { level }\end{array}$ & $R I$ & $\begin{array}{l}\text { Ecological risk } \\
\text { level }\end{array}$ \\
\hline$<40$ & Slight & $<150$ & Slight \\
$<80$ & Medium & $<300$ & Medium \\
$\geq 80$ & Strong & $\geq 300$ & Strong and above \\
\hline
\end{tabular}


$\mathrm{EDI}=\frac{C^{\mathrm{i}} \times \mathrm{FIR} \times \mathrm{ED} \times \mathrm{EF}}{\mathrm{WAB} \times \mathrm{TA}}$

$\mathrm{THQ}=\frac{\mathrm{EDI}}{\mathrm{RfD}}$

In Eqs. (4) and (5), EDI (estimated daily intake) represents the daily average intake of heavy metals $i\left(\mathrm{mg} \mathrm{kg}^{-1} \mathrm{~d}^{-1}\right) ; C^{i}$ is the average content of heavy metals $i$ in platycodon grandiflorum $\left(\mathrm{mg} \mathrm{kg}^{-1}\right) ; E F$ represents the frequency of exposure $\left(\mathrm{d} \mathrm{a}^{-1}\right) ; E D$ indicates the basic years (a); $T A$ indicates the contact time (d); WAB indicates the average body weight of adults, which is calculated in terms of $60 \mathrm{~kg}$; FIR indicates users' daily intake of herb based on Chinese Pharmacopoeia $\left(\mathrm{g}\right.$ person $\left.{ }^{-1} \mathrm{~d}^{-1}\right)$. In Formula (2); $T H Q$ represents the target hazard coefficient; $R f D$ is the daily maximum allowable intake of heavy metal $i\left(\mathrm{mg} \mathrm{kg}^{-1} \mathrm{~d}^{-1}\right)$, whose value refers to the longterm oral exposure reference dose prescribed by USEPA of the USA and the daily allowable intake prescribed by the WHO (USEPA, 1998). The criterion for evaluation using this model is that when $T H Q<1$, the effect of oral intake of heavy metal $i$ on human health is not obvious. When $T H Q>1$, the exposure of this pathway may cause non-carcinogenic risk.

When multiple heavy metals are present, they may cause more harm to the human body than single harmful heavy metal. Therefore, in order to evaluate the harm of various heavy metals to human health, we apply the total hazard index $H I$ to indicate the total size of non-carcinogenic risks under the pollution of various heavy metals. The formula is as follows:

$\mathrm{HI}=\sum_{\mathrm{i}=1}^{\mathrm{m}} \mathrm{THQ}_{\mathrm{i}}$

In Formula (6), $H I$ is the hazard index, and $T H Q_{i}$ is the target hazard coefficient of heavy metal $i$. When $H I \leq 1.0$, it means that the human body will not subject to obvious non-carcinogenic damage, and when $H I>1.0$, it indicates that the risk of harm to human health is very high.

Statistical analysis

All measurements were taken using triplicate samples. Data were expressed as mean \pm SD. All data were statistically processed using the SPSS 20.0.

\section{Results and discussion}

Heavy metals in the soil of Chinese herbal medicine planting area

The concentrations of heavy metals in herbal soils showed a large variation. The measured values of $\mathrm{Cr}$, $\mathrm{Ni}, \mathrm{Cu}, \mathrm{Zn}, \mathrm{As}, \mathrm{Cd}, \mathrm{Hg}$ and $\mathrm{Pb}$ in the collected soils samples are shown in Table 2. In this table, we listed the limits of heavy metal content stipulated in the

Table 2 The contents of 8 elements in soil

\begin{tabular}{|c|c|c|c|c|c|c|}
\hline \multirow[t]{2}{*}{ Elements } & \multicolumn{4}{|c|}{ Elements contents $\left(\mathrm{mg} \mathrm{kg}^{-1}\right)$} & \multirow{2}{*}{$\begin{array}{l}\text { Environmental } \\
\text { quality standard for } \\
\text { soils }^{\mathrm{a}} \\
\text { First-class National } \\
\text { Soil Environment } \\
\text { Standard }\end{array}$} & \multirow{2}{*}{$\begin{array}{l}\text { Risk control standard for soil } \\
\text { contamination of agricultural } \\
\text { land }^{\text {b }} \\
\text { Risk screening values }^{\#}\end{array}$} \\
\hline & Soil of AL & Soil of SB & Soil of RA & Soil of SG & & \\
\hline $\mathrm{Cr}$ & $12.02 \pm 0.49$ & $12.43 \pm 0.52$ & $17.72 \pm 0.65$ & $11.80 \pm 0.24$ & 90 & 150 \\
\hline $\mathrm{Ni}$ & $6.47 \pm 0.36$ & $6.25 \pm 0.24$ & $8.80 \pm 0.48$ & $6.18 \pm 0.23$ & 40 & 60 \\
\hline $\mathrm{Cu}$ & $5.38 \pm 0.32$ & $5.61 \pm 0.47$ & $8.62 \pm 2.79$ & $5.22 \pm 0.32$ & 35 & 50 \\
\hline $\mathrm{Zn}$ & $20.67 \pm 4.97$ & $22.60 \pm 4.48$ & $23.72 \pm 5.84$ & $20.62 \pm 3.2$ & 100 & 200 \\
\hline As & $4.44 \pm 0.41$ & $4.62 \pm 0.43$ & $5.19 \pm 0.43$ & $4.37 \pm 0.18$ & 15 & 40 \\
\hline $\mathrm{Cd}$ & $0.16 \pm 0.02$ & $0.17 \pm 0.01$ & $0.21 \pm 0.02 *$ & $0.16 \pm 0.02$ & 0.2 & 0.3 \\
\hline $\mathrm{Hg}$ & $0.16 \pm 0.17 *$ & $0.13 \pm 0.17$ & $0.40 \pm 0.30 *$ & $0.19 \pm 0.08 *$ & 0.15 & 1.3 \\
\hline $\mathrm{Pb}$ & $12.84 \pm 1.22$ & $12.07 \pm 0.68$ & $15.71 \pm 2.03$ & $12.84 \pm 0.96$ & 35 & 70 \\
\hline
\end{tabular}

Annotation: * means exceeding national Grade 1 soil standards; ${ }^{*}$ all the screened values were selected for non-paddy fields and the minimum value at the lowest $\mathrm{pH} ;{ }^{\mathrm{a}}$ reference (AEPA, 1995); ${ }^{\mathrm{b}}$ reference (Environment, 2018). Values were highlight with bold, which means higher than the standards instead of representing a statistical difference 
abolished Environmental Quality Standard for Soils (GB15618-1995) (AEPA, 1995) and the newly issued Soil Environmental Quality Risk Control Standard for Soil Contamination of Agricultural Land (GB156182018) (Environment, 2018). The levels of heavy metals in the soils of the four areas conformed to the two standards except Hg. The soil of RA planting area has a higher $\mathrm{Hg}$ content than that in other three areas $\left(0.40 \pm 0.30 \mathrm{mg} \mathrm{kg}^{-1}\right)$, and the SB soil has the lowest $\mathrm{Hg}$ content $\left(0.13 \pm 0.17 \mathrm{mg} \mathrm{kg}^{-1}\right)$. Supplementary Table 3 listed the information of the over-standard sample number and maximum over-standard multiple of soil samples. As it is known that the mean level for $\mathrm{Hg}$ in the world's soil is $0.03 \sim 0.10 \mathrm{mg} \mathrm{kg}^{-1}$, the background level for $\mathrm{Hg}$ in China is $0.038 \mathrm{mg} \mathrm{kg}^{-1}$, and the benchmark value for $\mathrm{Hg}$ in the eastern area of Hebei is $0.013 \mathrm{mg} \mathrm{kg}^{-1}$ (Hangxin et al., 2014). In this research, all the levels of $\mathrm{Hg}$ we determined in the soil were over the benchmark value, but below the control value, which indicated that there is a potential contamination of $\mathrm{Hg}$ in this area.

There are many sources of mercury pollution in the soil, among which human production and living are the main aspects. Jiang's research (Jiang et al., 2018) has suggested that, within the area he studies, the exhaust emission from industrial chimneys contributes to varying levels of mercury pollution in the soil. Song's data (Song et al., 2010) had shown that sewage irrigation was the main way to cause mercury pollution in the soil. A large amount of heavy metalcontaining wastewater discharged into rivers will result in mercury contamination of irrigation water; the amount of mercury deposited by the atmosphere into farmland is $3.54 \mathrm{~g} \mathrm{hm}^{-2}$, which is about twice the amount of mercury input into irrigation sewage and will lead to mercury pollution in soil (Jiang et al., 2018). Thus, finding and controlling mercury pollution sources may be a critical method to reduce soil heavy metal pollution in this area.

Ecological risk assessment of heavy metals in soil of herbal planting base

The method of potential ecological hazard index was used to evaluate the ecological risk of metal elements in soils. $C_{f}^{i}$ stands for average pollution coefficient, which resulted from comparing the measured values with the benchmark value of elements in the soil of eastern area of Hebei (Guo et al., 2007). As shown in Table 3, the levels of heavy metals in the soil were lower than the benchmark value except $\mathrm{Cd}$ and $\mathrm{Hg}$. The $\mathrm{Cd}$ and $\mathrm{Hg}$ contents generally exceeded the baseline values in the four sampling areas. This result suggested that there might be contamination of these two elements at the sample collection site. The $R I$ indices of the four sampling areas were 488.70, $728.81,1011.77$ and 597.73, respectively, which indicated that the soil faced great ecological risks of the heavy metals we determined. According to these results, the heavy metals $\mathrm{Hg}$ and $\mathrm{Cd}$ provide greater contribution to the total ecological hazards, about $80 \%$ ecological hazards deriving from $\mathrm{Hg}$. Considering the comparison of average concentrations with corresponding background values, $\mathrm{Cd}$ and $\mathrm{Hg}$ were regarded as the main pollutants in the herbal soils we studied.

Therefore, controlling the mercury content in the soil is a direct way to address the potential ecological risks in the region. Although the content of $\mathrm{Cd}$ (biotoxicity coefficient value: $\mathrm{Hg}=40>\mathrm{Cd}=30$ ) (Y. Liu, Qin, et al., 2018; Liu, Wang, et al., 2018) exceeded the reference value of this region, it did not exceed the national soil standards. However, the ecological risk of $\mathrm{Cd}$ in this region is also very significant. Cai et al. showed that the two elements $\mathrm{Hg}$ and $\mathrm{Cd}$ have the most serious external superposition, and the concentration of them in the shallow soil was higher than that in the deep (Cai et al., 2016). Sun et al. investigated the levels, sources, and spatial distribution of heavy metals in soils from a typical coal industrial city (he studied the same city as ours). They mentioned that the concentrations of metals were below the baseline values. However, most of the soil samples were contaminated with slightly to moderately levels of mercury and cadmium. This is consistent with the research results of this paper (Sun et al., 2019).

The application of risk screening values should be case-by-case. The contents of $\mathrm{Hg}$ and $\mathrm{Cd}$ in these four regions meet the soil risk screening criteria, but have a very strong ecological risk. In addition to their strong biotoxicity coefficient, a large part of the reason is related to the local reference value. The reference values of $\mathrm{Hg}$ and $\mathrm{Cd}$ in this selected area were $1.3 \times 10^{-2} \mathrm{mg} \mathrm{kg}^{-1}$ and $8.1 \times 10^{-2} \mathrm{mg} \mathrm{kg}^{-1}$, respectively (Guo et al., 2007). The measured values in the soil in this area are much higher than the 
Table 3 Ecological hazard assessment of heavy metal metals in soil

\begin{tabular}{|c|c|c|c|c|c|c|}
\hline \multirow[t]{2}{*}{ Elements } & \multicolumn{3}{|c|}{ Soil evaluation of AL } & \multicolumn{3}{|c|}{ Soil evaluation of SB } \\
\hline & $\mathrm{C}_{\mathrm{f}}^{\mathrm{i}}$ & $E_{\mathrm{r}}^{\mathrm{i}}$ & $R I$ & $\mathrm{C}_{\mathrm{f}}^{\mathrm{i}}$ & $E_{\mathrm{r}}^{\mathrm{i}}$ & $R I$ \\
\hline $\mathrm{Cr}$ & $0.18 \pm 0.01$ & 0.38 & 488.70 & $0.21 \pm 0.03$ & 0.42 & 728.81 \\
\hline $\mathrm{Ni}$ & $0.27 \pm 0.02$ & 1.31 & Strong ecological risk & $0.30 \pm 0.06$ & 1.49 & Strong ecological risk \\
\hline $\mathrm{Cu}$ & $0.28 \pm 0.02$ & 1.48 & & $0.32 \pm 0.05$ & 1.61 & \\
\hline $\mathrm{Zn}$ & $0.40 \pm 0.09$ & 0.43 & & $0.41 \pm 0.08$ & 0.41 & \\
\hline As & $0.66 \pm 0.06$ & 6.86 & & $0.71 \pm 0.06$ & 7.05 & \\
\hline $\mathrm{Cd}$ & $2.75 \pm 0.31 *$ & 84.11\# & & $2.03 \pm 0.23 *$ & 60.85 & \\
\hline $\mathrm{Hg}$ & $12.55 \pm 13.34 *$ & 391.11\# & & $16.34 \pm 14.97 *$ & 653.85\# & \\
\hline $\mathrm{Pb}$ & $0.64 \pm 0.06$ & 3.02 & & $0.62 \pm 0.04$ & 3.12 & \\
\hline \multirow[t]{2}{*}{ Elements } & \multicolumn{3}{|c|}{ Soil evaluation of RA } & \multicolumn{3}{|c|}{ Soil evaluation of SG } \\
\hline & $\mathrm{C}_{\mathrm{f}}^{\mathrm{i}}$ & $E_{r}^{i}$ & $R I$ & $\mathrm{C}_{\mathrm{f}}^{\mathrm{i}}$ & $E_{r}^{i}$ & $R I$ \\
\hline $\mathrm{Cr}$ & $0.27 \pm 0.01$ & 0.54 & 1011.77 & $0.18 \pm 0.00$ & 0.36 & 597.73 \\
\hline $\mathrm{Ni}$ & $0.37 \pm 0.03$ & 1.84 & Strong ecological risk & $0.26 \pm 0.01$ & 1.35 & Strong ecological risk \\
\hline $\mathrm{Cu}$ & $0.45 \pm 0.17$ & 2.27 & & $0.27 \pm 0.02$ & 1.42 & \\
\hline $\mathrm{Zn}$ & $0.45 \pm 0.13$ & 0.45 & & $0.40 \pm 0.06$ & 0.4 & \\
\hline As & $0.77 \pm 0.08$ & 7.71 & & $0.65 \pm 0.03$ & 6.59 & \\
\hline $\mathrm{Cd}$ & $2.54 \pm 0.28^{*}$ & 76.07 & & $2.65 \pm 0.29 *$ & 82.45\# & \\
\hline $\mathrm{Hg}$ & $22.97 \pm 16.84 *$ & 918.95\# & & $14.52 \pm 6.04 *$ & 501.95\# & \\
\hline $\mathrm{Pb}$ & $0.79 \pm 0.18$ & 3.93 & & $0.64 \pm 0.05$ & 3.21 & \\
\hline
\end{tabular}

Annotation: * means higher than the local surface reference value; \# indicates prominent ecological risk. Values were highlight with bold, which means higher than the standards instead of representing a statistical difference

reference values. The level of heavy metals in natural soil is low, while the heavy metals content in soil elevates due to artificial factors such as intensive agriculture, industrialization, urbanization (Bhatti et al., 2017; Sun et al., 2019). The contaminative of heavy metals in soil came from not only sewage irrigation and atmospheric deposition (Sun et al., 2019), but also the chemical fertilizers and pesticides, since these agrochemicals contain metals such as $\mathrm{Cr}$, $\mathrm{Cd}, \mathrm{Hg}, \mathrm{Pb}$ (Bhatti et al., 2016). Industry and agriculture in this research area are very developed. Therefore, all these human factors may induce the contents of $\mathrm{Hg}$ and $\mathrm{Cd}$ in the soil in this area exceeding the baseline value and pose a serious ecological risk. Further researches on the source of soil heavy metals are of great significance for controlling heavy metal pollution in the soil.
Contents of heavy metals in Chinese herbal medicine

As shown in Table 4, the content variation of $\mathrm{Cr}$ in Aster was relatively large, with a maximum value of $14.804 \mathrm{mg} \mathrm{kg}^{-1}$ and a minimum value of $0.742 \mathrm{mg} \mathrm{kg}^{-1}$. Its average value is significantly higher than that in other traditional Chinese medicine we determined. However, the limit value of this element is not stipulated in the pharmacopoeia. The toxicity of $\mathrm{Cr}$ increased along with the rise of acidity of the soil and closely related to its valence (do Nascimento et al., 2018). The toxicity of Cr (III) was less than that of $\mathrm{Cr}$ (VI) (Rizlan et al., 2007). In this paper, the total content of $\mathrm{Cr}$ was detected but not distinguish the valence state of $\mathrm{Cr}$.

The 2020 Edition of The Chinese Pharmacopoeia prescribed the limits of heavy metals and harmful elements in Chinese medicinal materials (Commission, 2020). The pharmacopoeia prescribed that the content of $\mathrm{Pb}$ shall not exceed $5 \mathrm{mg} \mathrm{kg}{ }^{-1}$, with $\mathrm{Cd}$ not exceeding $1 \mathrm{mg} \mathrm{kg}^{-1}$, As not exceeding $2 \mathrm{mg} \mathrm{kg}^{-1}$, 


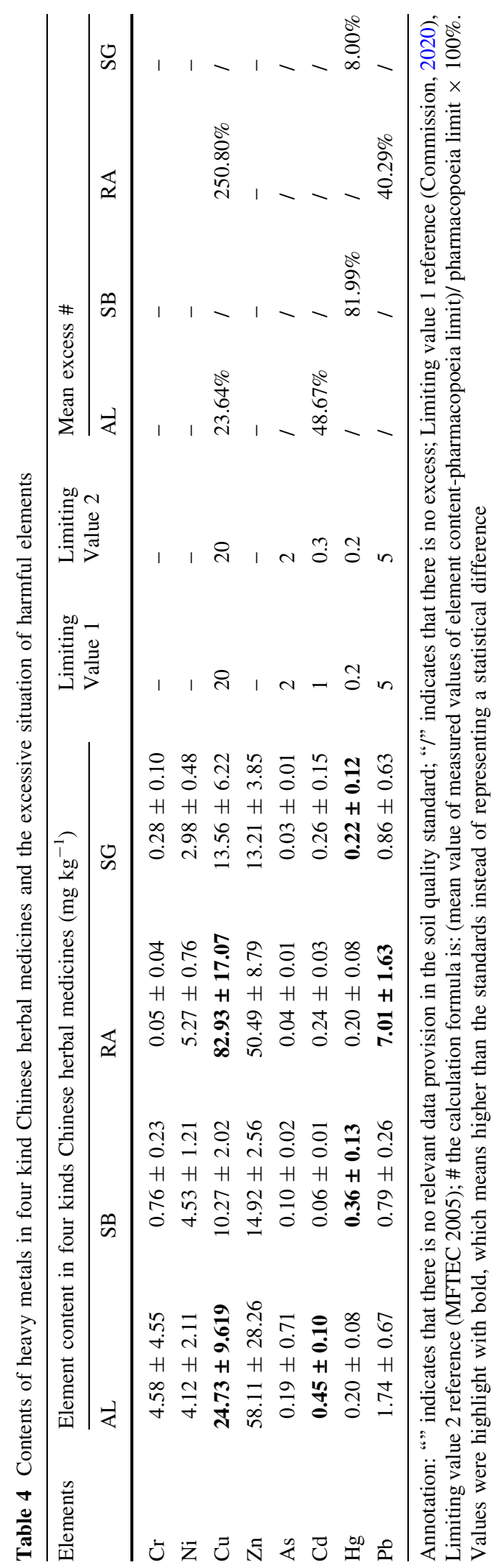


$\mathrm{Hg}$ not exceeding $0.2 \mathrm{mg} \mathrm{kg}^{-1}$, and $\mathrm{Cu}$ not exceeding $20 \mathrm{mg} \mathrm{kg}^{-1}$. The Green standards of medicinal plants and preparations for foreign trade and economy (MFTEC 2005) stipulated that the content of heavy metal $\mathrm{Cd}$ in Chinese herbal medicine should not exceed $0.3 \mathrm{mg} \mathrm{kg}^{-1}$; thus, this study adopted the standard as the limit value to calculate the excessive heavy metal content.

According to Table 4, the concentrations of heavy metals in herbs varied greatly. $\mathrm{Cu}$ content exceeded the standard by $23.64 \%$ in AL and by $250.80 \%$ in RA. Actually, the levels of $\mathrm{Cu}$ in all the samples of RA (111.89 $\mathrm{mg} \mathrm{kg}^{-1} \sim 53.44 \mathrm{mg} \mathrm{kg}^{-1}$ ) exceed acceptable level (these data were not shown in this paper). The level of $\mathrm{Pb}$ contained in RA exceeds the standard by $40.29 \%$. The Hg levels in SB and SG exceed the legal values by $81.99 \%$ and $8.00 \%$, respectively. In addition, the information of over-standard herbal samples is shown in Supplementary Table 5. As shown in Table 3, $\mathrm{C}_{\mathrm{f}}^{\mathrm{i}}$ is the result of the comparison between the measured value of heavy metals and the reference value. When $C_{f}^{i}$ is greater than 1 , it indicated that the content of the heavy metal exceeded the reference value. Therefore, the concentration of $\mathrm{Cd}$ in the soil is higher than the background value in the local soil, so is the $\mathrm{Hg}$ concentration. However, the $\mathrm{Cu}$ content in the soil was below the reference value (Guo et al., 2007). This suggests that the situation of excessive heavy metals in medicinal materials is not consistent with that in soil.

Chinese herbal medicines, as well as other plants, have various enrichment and absorption capacities of specific heavy metals (Peng et al., 2018; Sarma et al., 2011). Taking advantage of this peculiarity, some researchers have developed soil remediation technologies by plants (Ashwini Waoo 2011). Tang et al. showed that $\mathrm{Cd}$ had a higher translocation factors from soil to root in rice (Tang et al., 2019). Bonari et al. also mentioned that most of the trace elements analysis in the medicinal herb showed significant differences (Hypericum perforatum L.) (Bonari et al., 2018). He considered that to assure the quality of herbal products, edaphic conditions and soil geochemistry features of the cultivation areas should be nonnegligible (Bonari et al., 2018). As we all known, the heavy metal contents of plants are decisively influenced by the environment where they are grown, such as soil, irrigation water, air, agrochemicals, and other conditions (Bonari et al., 2018; Haidu et al., 2017; Zhang et al., 2016). Therefore, considering the characteristics of planting environment comprehensively, it is necessary to establish the site-specific screening value to cultivate qualified medicinal materials (Tang et al., 2019).

Health risk assessment of heavy metals in Chinese herbal medicine

There are excessive levels of many heavy metals in the Chinese herbal medicines we tested. Therefore, we want to know the health risk of these medicines by decoction. This study simulated the non-carcinogenic health risks that metal elements might cause using the target hazard quotients assessment model in Method 1.5. According to the provisions of The Chinese Pharmacopoeia (Commission, 2020), the average value of the maximum and minimum amounts prescribed in the pharmacopoeia was used as the food intake rate FIR in this evaluation model (7.5 g person $^{-1} \mathrm{~d}^{-1}$ for $\mathrm{AL}, 12.5 \mathrm{~g}$ person $^{-1} \mathrm{~d}^{-1}$ for $\mathrm{SB}$, $4.5 \mathrm{~g}_{\text {person }}{ }^{-1} \mathrm{~d}^{-1}$ for RA, $6.5 \mathrm{~g}$ person $^{-1} \mathrm{~d}^{-1}$ for $\mathrm{SG})$. We assumed other values as: exposure frequency $E F=90\left(\mathrm{~d} \mathrm{a}^{-1}\right)$; exposure duration $E D=30$ (a); exposure time $T A=30 \times 365(\mathrm{~d})$, average adult weight $\mathrm{WAB}=60(\mathrm{~kg})$; the reference does $R f D$ came from the weekly tolerable amount specified by the World Health Organization or the safety limit specified by the US Environmental Protection Agency (USEPA 2005).

In Table 5, the RfD and EDI values were shown. These two indicators descript the daily limited intake of heavy metals. As shown in Table 5, all the $T H Q$ values of heavy elements were less than 1 . The $H I$ values of the four Chinese herbal medicines were $8.84 \times 10^{-2}, 7.68 \times 10^{-2}, 9.53 \times 10^{-2}, 9.53 \times 10^{-2}$, respectively, all less than 1 . This means the daily intake of heavy metals meets international standards under the assumptions of this study. It suggests that the harmful elements ingested from the four Chinese herbal medicines would not pose a non-carcinogenic risk to human health according to the prescribed dose of Pharmacopoeia.

However, the order of $T H Q$ values is slightly different in special herb. In AL, the $T H Q$ values were ranked in the order of $\mathrm{As}>\mathrm{Cu}>\mathrm{Pb}>\mathrm{Cd}>\mathrm{Hg}>$ $\mathrm{Ni}>\mathrm{Zn}>\mathrm{Cr}$. Compared with Table 4 and Table 5, although the content of As conforms to the national 


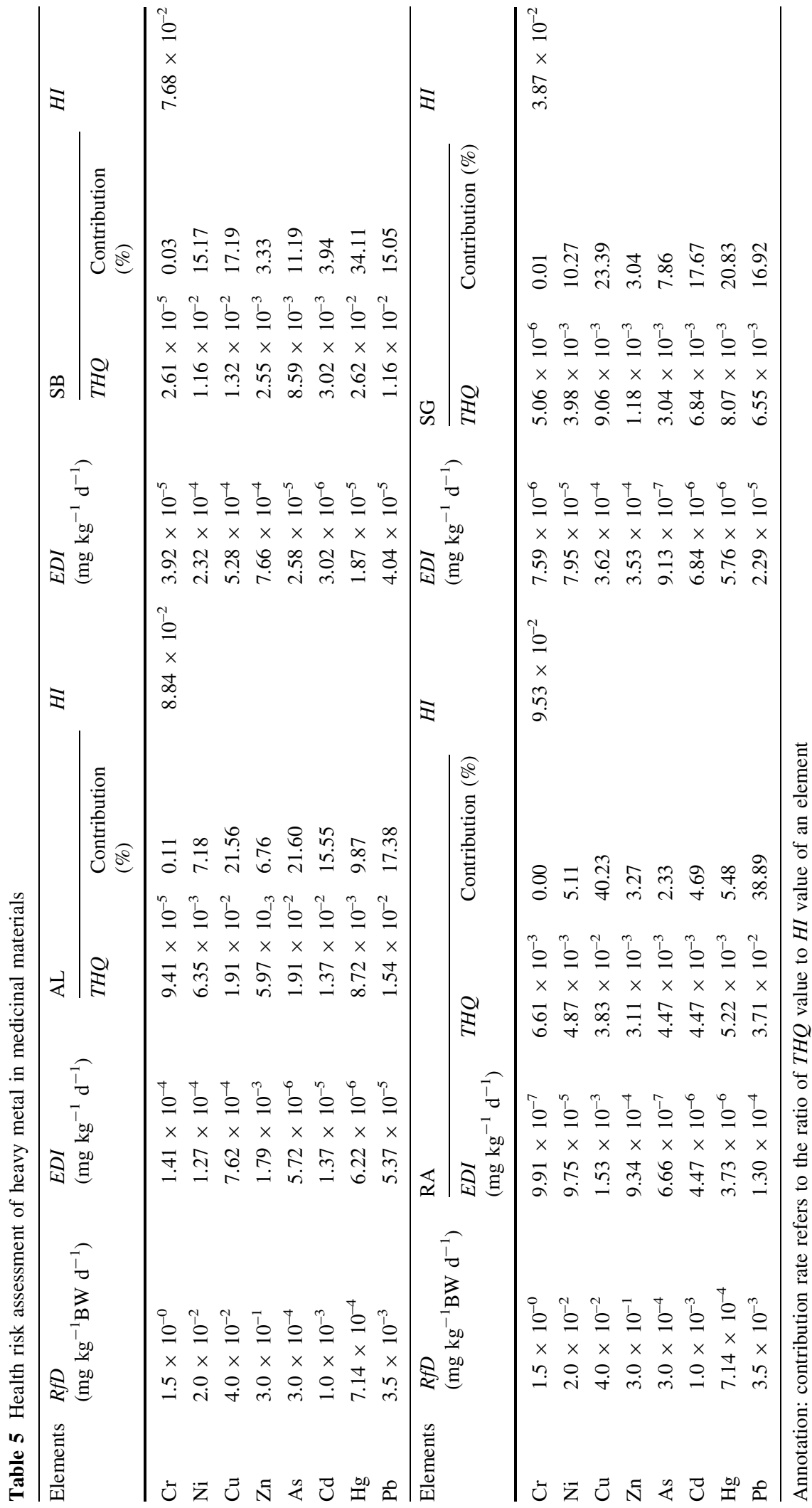


standard, its $E D I$ value is still very high and contributes the most to HI. The contribution rates for $H I$ of As and $\mathrm{Cu}$ reached $21.60 \%$ and $21.56 \%$, respectively. In SB, the $T H Q$ order was ranked $\mathrm{Hg}>\mathrm{Cu}>\mathrm{Ni}>\mathrm{As}>$ $\mathrm{Pb}>\mathrm{Cd}>\mathrm{Zn}>\mathrm{Cr}$. The $T H Q$ value of $\mathrm{Hg}$ was $2.62 \times 10^{-2}$, with a contribution rate of $34.11 \%$. In $\mathrm{RA}$, the $T H Q$ values of $\mathrm{Cu}$ and $\mathrm{Pb}$ were $3.83 \times 10^{-2}$ and $3.71 \times 10^{-2}$ and accounting for $40.23 \%$ and $38.89 \%$ of the $H I$ value contribution rate, respectively. The order of $T H Q$ values was $\mathrm{Cu}>\mathrm{Pb}>\mathrm{Hg}>\mathrm{Ni}>$ $\mathrm{Cd}>\mathrm{Zn}>\mathrm{As}>\mathrm{Cr}$. In $\mathrm{SG}$, the $T H Q$ were in the order of $\mathrm{Cu}>\mathrm{Hg}>\mathrm{Cd}>\mathrm{Pb}>\mathrm{Ni}>\mathrm{As}>\mathrm{Zn}>$ $\mathrm{Cr}$, with the contribution rate for the $H I$ value being $9.06 \times 10^{-3}$ of $\mathrm{Cu}$ and $8.07 \times 10^{-3}$ of $\mathrm{Hg}$.

Humans can be exposed to various environmental pollutants, including heavy metals, through a variety of pathways, such as skin contact, inhalation, and food chains. Oral ingestion is the main route of human exposure in humans compared with other routes (Khan et al., 2008). Therefore, this study has chosen oral health risk assessment. The $T H Q$ calculation in this paper was based on the data of adults, without considering the age or other factors. There was thus a certain deviation in the evaluation, which was similar to the previous studies (Tang et al., 2019). Heavy metal concentrations in herbs used to assess the health risk were influenced directly by heavy metal bioavailability in soils and translocation in plants (Huang \& Yuan 2016). Previous studies had also point out that $\mathrm{Cd}$ was more available to the rice plant than other heavy metals, such as $\mathrm{Zn}, \mathrm{Cu}, \mathrm{Cr}$, and $\mathrm{Pb}$ (Tang et al., 2019). Zuo et al. reported that the bioaccessibility of $\mathrm{Hg}$ was the lowest among the heavy metals they detected (Zuo et al., 2020). They also pointed out that the assessment of health risks based on the bioavailability of heavy metals could avoid excessively high-level estimation of health risks. In this study, the risk of non-carcinogenicity calculated in Table 5 was much lower than the danger level in the absence of bioavailability-based health risk assessment of heavy metals. The risk value may be lower, if the bioavailability, which value is usually lower than 1, is taken into account (Tang et al., 2019; Zhou et al., 2018; Zuo et al., 2020).

Although the heavy metals pose a high ecological risk, their concentrations in the soil meet the national standards according to current results. Herbs, planted in these soils, should meet the specifications theoretically. However, our results indicated that these four Chinese herbal materials had varying degrees in disqualification for heavy metals $\mathrm{Cu}, \mathrm{Cd}, \mathrm{Hg}$ or $\mathrm{Pb}$ excess. According to the hypothetical model, oral ingestion of herb heavy metals had no significant impact on human health according to the assuming model. Nevertheless, the selection of planting areas for Chinese herbal materials should take into account not only the contamination of heavy metals in soil, but also the specific enrichment ability of plants (Bonari et al., 2018; Tang et al., 2019; Zhang et al., 2016).

\section{Conclusion}

In the city of Qian' an, we explored the concentration of heavy metals in four Chinese herbal medicines and their native soil and evaluated potential ecological risk in soil and health risk in herbs. The result suggested that the contamination of heavy metals in herbs was not directly proportional to that in its native soil. On the one hand, the soil is exposed to significant pollution of $\mathrm{Hg}$ and $\mathrm{Cd}$, while the four herbs varied in contamination levels of $\mathrm{Cu}, \mathrm{Cd}, \mathrm{Hg}$ and $\mathrm{Pb}$. Thus, soil may not be the only sources of heavy metals for Chinese herbal medicines, and herbs which planted in the same environments may have different excessive levels and kinds of heavy metals. As a consequence, selective planting may help avoid the contamination of heavy metals. On the other hand, the potential ecological risk in soil and health risk in herbs was inconsistent. The mercury exhibited high ecological risk in the four planting areas by Hakanson's ecological risk assessment method. However, non-carcinogenic health risk assessment results showed that the heavy metals ingested by the four Chinese herbal medicines in accordance with the pharmacopoeia would not pose a non-carcinogenic risk to human health.

In the present study, the whole plant of herb is used for the measurement of heavy metal contents. However, in Chinese herbal medicine decoction, only specific parts, such as radix, are used in most cases. The average weight in China instead of that in Hebei Province was used in human health risk assessment. We consider neither the bioaccessibility of heavy metals in the food chain nor the fractions of heavy metals in the soil. All these might cause some uncertainty for the potential risk evaluation. Although samples were collected from one region in the city and there are thus certain limitations in this study, our research provides guidance for planting Chinese 
herbal medicines selectively for the safety of heavy metals, and exploring the comprehensive effects of soil, atmosphere, irrigation water, etc., on the content of heavy metals in plants.

Funding This work was supported by the research program of Hebei Province Commission of Population and Family Planning (Grant No. 20180749) and Hebei Food and Drug Administration Project (Grant No. ZD2015027).

Data availability The datasets used or analyzed during the current study are available from the corresponding author on reasonable request.

\section{Declarations}

Conflicts of interest The paper "Ecological and health risk assessment of heavy metals in soil and Chinese herbal medicines" has not been submitted elsewhere; it is not under review or published previously. The authors have no financial or proprietary interests in any material discussed in this article.

\section{References}

Adeyolanu, O. D., Kadiri, O. J., Are, K. S., Oluwatosin, G. A., \& Tejada Moral, M. (2016). Lead and cadmium contents in a medicinal plant/spice grown in an urban city of Nigeria. Cogent Food \& Agriculture, 2(1). https://doi.org/10.1080/ 23311932.2015.1136016.

AEPA (1995). Environmental quality standard for soils. GB15618-1995: State Environmental Protection Agency, People's Republic of China (PRC).

Ashwini Waoo, S. K., \& Ganguly, S. (2011). Unconventional Plant-based Remediation Technologies for Soil pollution at Contaminated Sites in Bhopal. International Journal of Engineering and Advanced Technology, 1(1), 41-44.

Barthwal, J., Nair, S., \& Kakkar, P. (2008). Heavy metal accumulation in medicinal plants collected from environmentally different sites. Biomedical and Environmental Sciences, 21(4), 319-324. https://doi.org/10.1016/s08953988(08)60049-5

Bhatti, S. S., Bhat, S. A., Kumar, V., Kaur, M., Minakshi, Sambyal, V., et al. (2017). Ecological risk assessment of metals in roadside agricultural soils: A modified approach. Human and Ecological Risk Assessment: An International Journal, 24(1),186-201. https://doi.org/10.1080/ 10807039.2017.1373328.

Bhatti, S. S., Sambyal, V., \& Nagpal, A. K. (2016). Heavy metals bioaccumulation in Berseem (Trifolium alexandrinum) cultivated in areas under intensive agriculture, Punjab. India. Springerplus, 5, 173. https://doi.org/10. 1186/s40064-016-1777-5

Bonari, G., Monaci, F., Nannoni, F., Angiolini, C., \& Protano, G. (2018). Trace element uptake and accumulation in the medicinal herb hypericum perforatum 1 across different geolithological settings. Biological Trace Element
Research, 189(1), 267-276. https://doi.org/10.1007/ s12011-018-1453-4

Cai, K., Duan, Y. M., Luan, W. L., Li, Q., \& Ma, Y. C. (2016). Geochemical behavior of heavy metals $\mathrm{Pb}$ and $\mathrm{Hg}$ in the farmland soil of Hebei plain. Geology in China, 4, 1420-1428.

Cheng, J. T. (2000). Review: drug therapy in Chinese traditional medicine. Journal of Clinical Pharmacology, 40(5), 445-450. https://doi.org/10.1177/00912700022009198

Commission, C. P. (2020). Pharmacopoeia of The Peoples's Republic OfChina: 2020. Volume 1: The Medicine Science and Technology Press of China.

do Nascimento, J. L., de Almeida, A.-A. F., Barroso, J. P., Mangabeira, P. A. O., Ahnert, D., Sousa, A. G. R., et al. (2018). Physiological, ultrastructural, biochemical and molecular responses of young cocoa plants to the toxicity of $\mathrm{Cr}$ (III) in soil. Ecotoxicology and Environmental Safety, 159(SEP.), 272-283. https://doi.org/10.1016/j.ecoenv. 2018.04.058.

Environment, M. o. E. a. (2018). Soil environmental quality risk control standard for soil contamination of agricultural land. GB 15618-2018: Ministry of Ecology and Environment, People's Republic of China (PRC).

Glavač, N. K., Djogo, S., Ražić, S., Kreft, S., \& Veber, M. (2017). Accumulation of heavy metals from soil in medicinal plants. Archives of Industrial Hygiene and Toxicology, 68(3), 236-244. https://doi.org/10.1515/aiht2017-68-2990

Guo, H., Ma, Z., Hao, J., Gao, H., \& Wang, S. (2007). Characteristics and Significance of reference values of the geochemical elements in soil samples from eastern hebei province. Rock And Mineral Analysis, 26(4), 281-286. (Chinese).

Haidu, D., Parkanyi, D., Moldovan, R. I., Savii, C., Pinzaru, I., Dehelean, C., et al. (2017). Elemental characterization of romanian crop medicinal plants by neutron activation analysis. Journal of Analytical Methods in Chemistry, 2017, 9748413. https://doi.org/10.1155/2017/9748413

Hakanson, L. (1980). An ecological risk index for aquatic pollution control. A sedimentological approach. Water Research. https://doi.org/10.1016/0043-1354(80)90143-8

Hangxin, C., Kuo, L., Min, Li., Ke, Y., Fei, L., \& Xiaomeng, C. (2014). Geochemical background and baseline value of chemical elements in urban soil in China. Earth Science Frontiers, 21(3), 265-306. https://doi.org/10.13745/j.esf. 2014.03.028

Hu, W., Chen, Y., Huang, B., \& Niederman, S. (2014). Health risk assessment of heavy metals in soils and vegetables from a typical greenhouse vegetable production system in China. Human \& Ecological Risk Assessment an International Journal, 20(5-6), 1264-1280. https://doi. org/10.1080/10807039.2013.831267

Jalali, M., \& Karimi Mojahed, J. (2020). Assessment of the health risks of heavy metals in soils and vegetables from greenhouse production systems in Iran. International Journal of Phytoremediation, 22(8), 834-848. https://doi. org/10.1080/15226514.2020.1715917

Jiang, X., Zou, B., Feng, H., Tang, J., Tu, Y., \& Zhao, X. (2018). Spatial distribution mapping of $\mathrm{Hg}$ contamination in subclass agricultural soils using GIS enhanced multiple linear 
regression. Journal of Geochemical Exploration, 196, 1-7. https://doi.org/10.1016/j.gexplo.2018.10.002

Khan, S., Cao, Q., Zheng, Y. M., Huang, Y. Z., \& Zhu, Y. G. (2008). Health risks of heavy metals in contaminated soils and food crops irrigated with wastewater in Beijing China. Environmental Pollution, 152(3), 686-692. https://doi.org/ 10.1016/j.envpol.2007.06.056

Li, Y., Liu, X., Guo, L., Li, J., Zhong, D., Zhang, Y., et al. (2020). Traditional Chinese herbal medicine for treating novel coronavirus (COVID-19) pneumonia: Protocol for a systematic review and meta-analysis. Systematic Reviews, 9(1). https://doi.org/10.1186/s13643-020-01343-4.

Li, Z., Ma, Z., van der Kuijp, T. J., Yuan, Z., \& Huang, L. (2014). A review of soil heavy metal pollution from mines in China: pollution and health risk assessment. Science of the Total Environment, 468-469, 843-853. https://doi.org/ 10.1016/j.scitotenv.2013.08.090

Liu, C., Qin, J., Dou, X., Yang, M., \& Sun, X. (2018). Extrinsic harmful residues in Chinese herbal medicines: types, detection, and safety evaluation. Chinese Herbal Medicines, 10(2), 117-136. https://doi.org/10.1016/j.chmed. 2018.02.002

Liu, M., Gao, Y., Yuan, Y., Yang, K., Shi, S., Zhang, J., et al. (2020). Efficacy and safety of integrated traditional Chinese and western medicine for corona virus disease 2019 (covid-19): A systematic review and meta-analysis. Pharmacological Research, 158, 104896. https://doi.org/ 10.1016/j.phrs.2020.104896

Liu, Y., Wang, Q., Zhuang, W., Yuan, Y., Yuan, Y., Jiao, K., et al. (2018). Calculation of Thallium's toxicity coefficient in the evaluation of potential ecological risk index: A case study. Chemosphere, 194, 562-569. https://doi.org/10. 1016/j.chemosphere.2017.12.002

Long, Z., Huang, Y., Zhang, W., Shi, Z., Yu, D., Chen, Y., et al. (2021). Effect of different industrial activities on soil heavy metal pollution, ecological risk, and health risk. Environmental Monitoring and Assessment, 193(1), 20. https://doi. org/10.1007/s10661-020-08807-z

MFTEC (2005). Green Trade Standards of Importing Exporting Medicinal Plants Preparations. WM/T2-2004: Beijing State Ministry of Foreign Trade and Economic Cooperation

Mohammadi, A. A., Zarei, A., Esmaeilzadeh, M., Taghavi, M., Yousefi, M., Yousefi, Z., et al. (2020). Assessment of Heavy Metal Pollution and Human Health Risks Assessment in Soils Around an Industrial Zone in Neyshabur Iran. Biological Trace Element Research, 195(1), 343-352. https://doi.org/10.1007/s12011-19-01816-1

Nagajyoti, P. C., Lee, K. D., \& Sreekanth, T. V. M. (2010). Heavy metals, occurrence and toxicity for plants: a review. Environmental Chemistry Letters, 8(3), 199-216. https:// doi.org/10.1007/s10311-010-0297-8

Peng, W., Li, X., Xiao, S., \& Fan, W. (2018). Review of remediation technologies for sediments contaminated by heavy metals. Journal of Soils and Sediments. https://doi. org/10.1007/s11368-018-1921-7

Rizlan, B. L., Obraztsova, A., Mackey, M. R., Ellisman, M. H., \& Tebo, B. M. (2007). Toxicity of Cr(III) to Shewanella sp strain MR-4 during $\mathrm{Cr}(\mathrm{VI})$ reduction. Environmental Ence \& Technology, 41(1), 214-220. https://doi.org/10.1021/ es0622655
Sarma, H., Deka, S., Deka, H., \& Saikia, R. R. (2011). Accumulation of heavy metals in selected medicinal plants. Reviews of Environmental Contamination and Toxicology, 214, 63-86. https://doi.org/10.1007/978-1-4614-0668-6_4

Song, Z., Luan, W., Cui, X., \& Li, S. (2010). An analysis of the sources of heavy metals in soils of eastern Hebei plain. Geology in China, 37(5), 1530-1538. (Chinese).

Sun, L., Guo, D., Liu, K., Meng, H., Zheng, Y., Yuan, F., et al. (2019). Levels, sources, and spatial distribution of heavy metals in soils from a typical coal industrial city of Tangshan, China. CATENA, 175, 101-109. https://doi.org/10. 1016/j.catena.2018.12.014

Tang, L., Deng, S., Tan, D., Long, J., \& Lei, M. (2019). Heavy metal distribution, translocation, and human health risk assessment in the soil-rice system around Dongting Lake area China. Environmental Science and Pollution Research International, 26(17), 17655-17665. https://doi.org/10. 1007/s11356-019-05134-w

Ur Rehman, Z., Khan, S., Tahir Shah, M., Brusseau, M. L., Akbar Khan, S., \& Mainhagu, J. (2018). Transfer of heavy metals from soils to vegetables and associated human health risks at selected sites in Pakistan. Pedosphere, 28(4), 666-679. https://doi.org/10.1016/s1002-0160(17)60440-5.

USEPA. (1998). Guidelines for the health risk assessment of chemical mixtures[R]. US Environmental Protection Agency.

USEPA. (2005). Guidelines for carcinogen risk assessment (Sept. 24). Federal Registar, 51, 636-640.

WHO (1996). WHO publication: Trace Elements in Human Nutrition and Health. Nutrition Research Newsletter.

Yang, Q., Li, Z., Lu, X., Duan, Q., Huang, L., \& Bi, J. (2018). A review of soil heavy metal pollution from industrial and agricultural regions in China: Pollution and risk assessment. Science of the Total Environment, 642, 690-700. https://doi.org/10.1016/j.scitotenv.2018.06.068

Zeiner, M., \& Juranović Cindrić, I. (2017). Review - trace determination of potentially toxic elements in (medicinal) plant materials. Analytical Methods, 9(10), 1550-1574. https://doi.org/10.1039/c7ay00016b

Zhang, W., You, M., \& Hu, Y. (2016). The distribution and accumulation characteristics of heavy metals in soil and plant from Huainan coalfield China. Environmental Progress \& Sustainable Energy, 35(4), 1098-1104. https://doi. org/10.1002/ep.12336

Zhou, L., Wang, S., Hao, Q., Kang, L., Kang, C., Yang, J., et al. (2018). Bioaccessibility and risk assessment of heavy metals, and analysis of arsenic speciation in Cordyceps sinensis. Chin Med, 13, 40. https://doi.org/10.1186/ s13020-018-0196-7

Zuo, T. T., Qu, H. R., Jin, H. Y., Zhang, L., Luo, F. Y., Yu, K. Z., et al. (2020). Innovative health risk assessments of heavy metals based on bioaccessibility due to the consumption of traditional animal medicines. Environmental Science and Pollution Research International, 27(18), 22593-22603. https://doi.org/10.1007/s11356-020-08769-2

Publisher's Note Springer Nature remains neutral with regard to jurisdictional claims in published maps and institutional affiliations. 